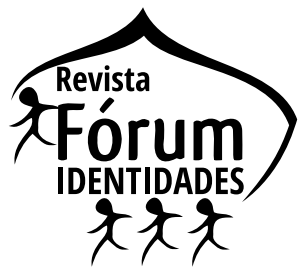

\title{
QUE CORPO É ESSE NA LITERATURA CONTEMPORÂNEA ESCRITA POR MULHERES?'
}

\section{WHAT BODY IS THAT IN THE CONTEMPORARY LITERATURE WRITTEN BY WOMEN?}

\author{
Maria do Rosário A. Pereira²
}

Resumo: O objetivo deste artigo é, a partir de uma tipologia de corpos elencada por Elódia Xavier em Que corpo é este? O corpo no imaginário feminino (2007; 2021, 2ª edição), propor uma leitura transversal entre as categorias por ela apresentadas no que se refere ao corpo na literatura de autoria feminina contemporânea. O corpus escolhido é composto por: "Pomba enamorada ou Uma história de amor", de Lygia Fagundes Telles, em que a protagonista apresenta-se ao mesmo tempo como um corpo disciplinado e imobilizado; "Bom partido", de Lorena Otero, em que há um corpo refletido ao início que caminha para se tornar um corpo liberado; e, por fim, A ponta do silêncio, de Valesca de Assis, em que o corpo envelhecido torna-se um corpo violento com vistas a tornar-se, ainda, um corpo liberado. Os resultados apontam para a multiplicidade de representações do corpo feminino na literatura escrita por mulheres.

Palavras-chave: Corpo feminino. Literatura de autoria feminina. Literatura brasileira.

\begin{abstract}
The objective of this paper is, based on a typology of bodies listed by Elódia Xavier in Que corpo é este? O corpo no imaginário feminino (2007; 2021, 2nd edition), proposes a cross-sectional reading between the categories presented by her with regard to the body in the literature of contemporary female authorship. The chosen corpus is composed of: "Pomba enamorada ou Uma história de amor", by Lygia Fagundes Telles, in which the protagonist presents herself at the same time as a disciplined and immobilized body; "Bom partido", by Lorena Otero, in which there is a body reflected at the beginning that is going to become a liberated body; and, finally, $A$ ponta do silencio, by Valesca de Assis, in which the aged body becomes a violent body with a view to becoming, still, a liberated body. The results point to the multiplicity of representations of the female body in the literature written by women.
\end{abstract}

Keywords: Feminine Body. Female Authorship Literature. Brazilian Literature.

\footnotetext{
${ }^{1}$ Artigo recebido em 13 de fevereiro de 2021 e aceito em 10 de abril de 2021.

2 Doutora em Letras - Estudos Literários pela UFMG; professora dos cursos técnicos e de graduação em Letras no Centro Federal de Educação Tecnológica de Minas Gerais - CEFET-MG, e do Programa de Pós-Graduação em Letras da Universidade Federal de Viçosa - UFV. ORCID: https://orcid.org/0000-0002-4797-5724. ResearcherID: AAV-2536-2020. E-mail: mariadorosario58@gmail.com.
} 
O título deste artigo é uma clara alusão à obra Que corpo é esse? O corpo no imaginário feminino, publicado por Elódia Xavier, pela primeira vez, em 2007 pela saudosa Editora Mulheres, e que sai agora em sua $2^{a}$ edição ampliada (2021, Oficina Raquel). Baseada em estudos sociológicos de Arthur Frank, Xavier expande as formulações do pesquisador, ao apontar possibilidades de leitura no que se refere aos distintos modos de apresentação do corpo feminino na literatura feita por mulheres. O corpus utilizado pela pesquisadora abarca contos e romances de escritoras brasileiras, desde o começo do século XX até o começo dos anos 2000. Esta segunda edição traz o acréscimo de estudos sobre Alina Paim (trilogia publicada nos anos 1960) e sobre um romance de Ana Maria Machado, Infâmia, o único da obra publicado após o fim do primeiro decênio dos 2000 - em 2011.

$\mathrm{Na}$ obra em xeque, Xavier trabalha com o corpo feminino em suas múltiplas representações, as quais convergem, de algum modo, para a percepção do corpo como local de inscrições culturais, políticas e sociais. É interessante notar que, atualmente, o próprio movimento feminista, em suas mais diversas manifestações, tem dado ênfase ao corpo como performance e como instrumento de reivindicação política. Na literatura de autoria feminina tal movimento não é diferente: nas últimas décadas, tem se destacado o número de contos e romances que tratam, por exemplo, de temas espinhosos ligados ao corpo feminino, sobretudo aqueles relacionados à violência física, como estupro e feminicídio. ${ }^{3} \mathrm{O}$ livro de Xavier parece ter antecipado, em alguma medida, o que viria a ser ponto nevrálgico na produção de mulheres dos anos 2000 para a frente.

As categorias estabelecidas pela pesquisadora são: corpo invisível, corpo subalterno, corpo disciplinado, corpo imobilizado, corpo envelhecido, corpo refletido, corpo violento, corpo degradado, corpo erotizado, corpo liberado e corpo caluniado. Longe de pretender esgotar todas as possibilidades de leitura sobre o corpo feminino na literatura, Xavier aponta para a multiplicidade dessas representações e, neste artigo, investigo como uma mesma representação pode conter diferentes facetas. Isso mostra que a tipologia expressa pela autora não é estanque, ao contrário, implica dinamicidade e múltiplas leituras. Sob essa perspectiva, proponho-me a uma breve análise de três produções literárias - dois contos e um romance - que ilustram esse entrecruzamento profícuo entre tais corpos: "Pomba enamorada ou Uma história de amor", de Lygia Fagundes Telles, publicado em 1977 na coletânea Seminário dos ratos; "Bom partido", de Lorena Otero, publicado em 2019 na coletânea Osso de baleia; e, finalmente, o romance $A$ ponta do silêncio, de Valesca de Assis, publicado em 2016.

\footnotetext{
${ }^{3}$ Destaque-se, quanto à temática do estupro, os romances Por cima do mar, de Deborah Dornellas (2019); O peso do pássaro morto, de Aline Bei (2017), e A vista chinesa, de Tatiana Salem Lévy (2021). Quanto ao feminicídio, Mulheres empilhadas, de Patrícia Melo (2019), aborda essa questão de modo enfático - na montagem do romance a autora inseriu, entre os capítulos, notícias verídicas de jornais sobre mulheres brutalmente assassinadas por seus parceiros.
} 


\section{Uma tipologia que questiona a opressão de gênero}

Antes, no entanto, de passar para a leitura dos referidos textos literários, vale a pena apresentar brevemente algumas dessas categorias de corpos elencados por Xavier, que ilustra a teoria com textos literários e os compara. O primeiro corpo apresentado na obra é o corpo invisível, o qual remete à inexistência de algumas personagens exatamente em decorrência de sua invisibilidade social. Os exemplos citados estão no romance $A$ intrusa, de Júlia Lopes de Almeida, e em um conto de Marilene Felinto, "Muslim: woman". No primeiro, a protagonista, Alice, mesmo sendo uma presença quase "imaterial", conquista Argemiro; no segundo, narra-se o encontro entre duas mulheres de culturas diferentes, uma ocidental e outra oriental. A narradora não se sente vista pelo marido, e essa falta de reconhecimento faz com que ela sinta inveja da suposta proteção que os trajes da oriental lhe proporcionam. Sugere-se, no conto, a impossibilidade da mulher como sujeito e detentora do próprio destino, o que é, ao mesmo tempo, fruto das injunções sociais que confinam a mulher a tal invisibilidade. Na sequência, apresenta-se o corpo subalterno, exemplificado por Quarto de despejo, de Carolina Maria de Jesus. A subalternidade se expressa tanto pelo preconceito racial quanto pela situação de penúria econômica à que a narradora do diário, a própria Carolina, se vê submetida.

Quanto ao corpo disciplinado, um dos quais nos interessa de modo mais próximo neste trabalho, Xavier ilustra com a personagem Macabéa, de $A$ bora da estrela, de Clarice Lispector. Partindo do conceito de corpos dóceis, de Michel Foucault, e da ideia da "dominação masculina", expressa por Pierre Bourdieu, a pesquisadora chama a atenção para o adestramento a que o corpo feminino é submetido, por meio de uma violência simbólica e sistemática. Neste ponto, julgo oportuno trazer à lume o conceito de "tecnologia de gênero" tão bem expresso por Teresa de Lauretis. Também a partir de Foucault e sua "tecnologia sexual", a pesquisadora salienta o fato de que a história da sexualidade não é a mesma para homens e mulheres e, para além de toda a contribuição teórica de Foucault sobre os cerceamentos à sexualidade humana, não se pode desconsiderar que, para ele, o poder é neutro. Afirma Lauretis: “[...] lá [em Foucault] a sexualidade não é entendida como 'gendrada', como tendo uma forma masculina e outra feminina, e sim como idêntica para todos - e consequentemente masculina.” (LAURETIS, 2019, p. 136) Isso implica o não reconhecimento das especificidades das experiências vividas por homens e mulheres; assim, ao considerá-los em certa medida iguais, deixa-se de lado formas e sistemas opressivos que contribuíram para a manutenção da mulher num lugar social à margem. Em diálogo indireto com essa teoria, na leitura de Xavier, é imprescindível a associação que ela faz, a partir de Bourdieu e do próprio Arthur Frank, entre a naturalização das regras 
por parte dos oprimidos e sua carência, já que é por causa desta carência que a aceitação a regras, sejam elas explícitas ou tácitas, faz-se no cerne da sociedade. Desse modo, não há questionamentos - se Macabéa, conforme Xavier, nunca questionara as ordens da tia falecida, tampouco a Pomba enamorada de Fagundes Telles questiona seu lugar na sociedade e, principalmente, seu "destino de mulher" que luta por seu grande amor, como se verá adiante.

Em diálogo com o corpo disciplinado tem-se o corpo imobilizado, espécie de ápice do primeiro. Se o corpo disciplinado pode, eventualmente, reagir, como demonstra Xavier por meio de exemplos como "A confissão de Leontina”, de Lygia Fagundes Telles, e "I love my husband", de Nélida Piñon, não existe essa possibilidade para um corpo que permanece totalmente preso às amarras sociais. Chamo a atenção para o fato de que, novamente, fazem-se pertinentes as considerações de Lauretis: partindo de pressupostos, hoje, já largamente difundidos pelas teorias críticas feministas - i) gênero é representação;. ii) a representação de gênero é sua construção; e iii) a construção de gênero se dá em vários lugares, inclusive de ordem epistemológica - , a pesquisadora destaca que as tecnologias do gênero, tais como o cinema, as narrativas e a teoria, juntamente com discursos institucionais - difundidos, por exemplo, pela Igreja e pela família -, são responsáveis por representações de gênero que são incutidas no imaginário, inclusive no imaginário feminino. Daí o último pressuposto da teoria de Lauretis, a saber: a construção de gênero também se faz por meio de sua desconstrução, o que implica propor formas de desestabilizar a representação, ou melhor, representações consagradas, estereotipadas no que se refere aos papéis sociais incutidos às mulheres. Algumas das novas representações do corpo feminino na literatura contemporânea apontam exatamente para essa desconstrução que as mulheres têm promovido via texto literário, como em "Bom partido", analisado adiante, no qual a personagem coloca em xeque todos os valores introjetados ao longo do tempo e reforçados em um relacionamento que, ao contrário de promover seu crescimento, só contribuía para diminuí-la.

\section{O corpo disciplinado em "Pomba enamorada ou uma história de amor"}

Passemos agora à análise do corpus selecionado. No conto de Fagundes Telles, tem-se uma protagonista, sem nome, e que se autointitula "Pomba enamorada”, apaixonada por um rapaz, Antenor, que não lhe corresponde afetivamente. O perfil da protagonista já dá indícios de seu lugar social: trata-se de uma moça humilde e sem muita instrução, pois tem uma falha no dente e é, no início do conto, aspirante a cabeleireira. A ideia de sacrifício perpassa toda a narrativa: sendo do signo de Capricórnio, a personagem teria de "lutar o dobro para vencer". Todos 
os seus anseios resumem-se em conquistar um homem que vira uma única vez num baile e de quem recebera um rápido elogio. A ideia de amor platônico e de uma romantização que permeiam o conto relacionam-se às inúmeras reproduções culturais acessadas e tomadas como modelo pela protagonista, bem como discursos do senso comum que remetem à ideia de "alma gêmea" e "par perfeito".

A personagem lygiana é uma personagem que se encontra entre dois paradigmas: ao mesmo tempo que, nos anos 1970, houve um avanço nas pautas feministas no que se refere aos diretos reprodutivos da mulher e à sua sexualidade, no Brasil, a baixa escolaridade feminina ainda era evidente, pois as mulheres começavam a adentrar as universidades. Assim, a Pomba enamorada deixa-se levar por modelos estabelecidos. Ela é fã de Catherine Duneauve, ícone do cinema francês, e lê a revista Verdades secretas, cujo sugestivo título é uma alusão às revistas femininas que reproduziam estereótipos e clichês, com fórmulas para que as mulheres obtivessem sucesso com os homens, fórmulas estas que passavam pela manutenção de padrões estéticos vigentes e pela receita de "agradar" ao homem. De acordo com Naomi Wolf, em $O$ mito da beleza:

Estamos em meio a uma violenta reação contra o feminismo que emprega imagens da beleza feminina como uma arma política contra a evolução da mulher: o mito da beleza. Ele é a versão moderna de um reflexo social em vigor desde a Revolução Industrial. À medida que as mulheres se liberaram da Mística Feminina da domesticidade, o mito da beleza invadiu esse terreno perdido, expandindo-se enquanto a mística definhava, para assumir sua tarefa de controle social (WOLF, 2018, p. 26-27).

A primeira edição desta obra data de 1991, mas as considerações acima permanecem bastante atuais. Quando o sistema percebeu que as mulheres não mais permaneceriam presas à esfera doméstica e que, cada vez mais, adentravam o mundo do trabalho, isto é, frequentavam a esfera pública, buscou novas estratégias de capitalizar este público. Daí as indústrias de cosméticos e as propagandas direcionadas à beleza feminina e sua importância para a realização pessoal e perfeita adequação social das mulheres crescerem vertiginosamente. No conto em estudo, nota-se que Pomba Enamorada era muito suscetível a essas influências, as quais acessava por meio de produtos culturais que, em grande medida, fortalecem a introjeção de valores.

No que se refere à atriz mencionada no conto, Isabelle Anchieta, em Imagens da mulher no Ocidente, compilação em três volumes, destaca, no tomo 3 dedicado às Stars de Hollywood, que as estrelas de cinema compunham uma espécie de "estereótipo personalizado", "universalidade com rosto", sendo modelos não só no que se refere à aparência física, mas também ao comportamento. Assim, ficam claras as influências culturais estrangeiras e midiáticas e o poder das ima- 
gens repassadas pela televisão e pelo cinema. Além da revista mencionada acima, a personagem escuta um programa de rádio intitulado "Intimidade no ar": vê-se, no conto, rádio, TV e cinema funcionando como "tecnologias de gênero", conforme preconizado por Lauretis.

A Igreja também aparece como instituição modelar das atribuições de gênero, e o destino almejado por Pomba enamorada é o do casamento. Há alusões a essa instituição, inclusive no que se refere à ideia sacrificial que perpassa o conto, conforme mencionado: a personagem faz uma novena milagrosa de Santo Antônio (ideia de um milagre, de vencer o impossível) na Igreja dos Enforcados, cujo santo padroeiro também tem uma história de sacrifício. Além disso, vários discursos do senso comum perpassam o imaginário da moça, como o da astrologia (associa eventos às relações entre os signos), da umbanda, do tarô - ela faz simpatias, despachos, promessas para santos católicos, tudo com o intuito de alcançar seu objetivo. Também acompanha dicas de uma obra erótica, do tipo "como segurar seu homem". A menção ao tarô no final do conto - anos depois, casada com outro homem, mãe de família e agora avó, o que dá indícios da passagem do tempo - é emblemática: não há como não nos lembrarmos de "A cartomante", de Machado de Assis, e $A$ hora da estrela, de Clarice Lispector. Durante toda sua vida, Pomba enamorada jamais perdera Antenor de vista ele seguira sua vida em outra cidade e tornara-se pai de gêmeas. Em todos os momentos significativos de sua vida, Pomba enamorada lhe enviava um cartão ou um presente. Assim, a personagem sempre recorre a artifícios da ordem do miraculoso e do transcendental na tentativa de conquistar Antenor e, ao final, pensa compreender o que o tarô supostamente lhe sugere:

A mulher embaralhou as cartas encardidas, espalhou tudo na mesa e avisou que se ela fosse no próximo domingo à estação rodoviária veria chegar um homem que iria mudar por completo sua vida, Olha ali, o Rei de Paus com a Dama de Copas do lado esquerdo. Ele devia chegar num ônibus amarelo e vermelho, podia ver até como era, os cabelos grisalhos, costeleta. O nome começava por A, olha aqui o Ás de Espadas com a primeira letra do seu nome. Ela riu seu risinho torto (a falha do dente já preenchida, mas ficou o jeito) e disse que tudo isso era passado, que já estava ficando velha demais pra pensar nessas bobagens mas no domingo marcado deixou a neta com a comadre, vestiu o vestido azul-turquesa das bodas de prata, deu uma espiada no horóscopo do dia (não podia ser melhor) e foi (TELLES, 1998, p. 83).

O final do conto reitera a ideia de sacrifício anteriormente mencionada, e o corpo disciplinado, acostumado a enquadrar-se em esquemas preestabelecidos socialmente, permanece em busca de preencher o ideal de amor 
romântico, mesmo que na vida real só tenha ouvido negativas de Antenor - e há um contraste interessante entre as duas personagens no que se refere à linguagem: ele usa palavrões e responde às investidas da moça de modo "curto e grosso", ao passo que ela é a imagem da própria delicadeza, o que é reiterado no início do conto, inclusive, pelo fato de ser virgem. Também o comportamento trágico de Pomba Enamorada reitera o que foi dito: quando Antenor se casa, ela tenta suicídio, o que dá contornos ainda mais dramáticos à busca desenfreada da personagem. Destaque-se, ainda, a segunda parte do título do conto - "...ou uma história de amor" -, absolutamente irônico no contexto, uma vez que a realização amorosa não acontece, ainda que Pomba Enamorada se apegue a essa possibilidade até o final de sua vida.

Assim, se o corpo disciplinado sofre a interferência de injunções sociais, também o corpo refletido e o corpo envelhecido tangenciam representações que são faces da mesma moeda: enquanto o primeiro é centrado em valores que são referência para a indústria cultural e que circulam livremente pela mídia, o segundo é a imagem da própria deterioração, uma vez que a mulher velha é vista como descartável socialmente por não atender mais aos anseios da sociedade capitalista, que vê a mulher como um objeto sempre à disposição do prazer masculino. A sombra das vossas asas, de Fernanda Young, romance analisado por Xavier (2007), traz a protagonista Carina, uma jovem gorda e feia que se apaixona por um fotógrafo de celebridades e se transforma em uma beldade para conquistá-lo. Ele se apaixona, então, por uma beleza construída, arquitetada por procedimentos cirúrgicos e pelo uso de cosméticos. A tão almejada felicidade não é alcançada, já que a relação dos dois é doentia, numa espécie de codependência. Xavier comenta:

O corpo refletido é sempre desejante, a fim de manter sua carência consciente. A cultura do consumo encurta o tempo e o espaço entre o desejo e sua realização. (...) (XAVIER, 2007, p. 112)

O corpo de Carina é como um espelho que reflete a imagem de Lee Miller e de tudo aquilo que ela consome. Ela vai adquirir novos habitus que, segundo Bourdieu, através de certa mobilidade, refletem aparências de outras classes ou de outras pessoas (XAVIER, 2007, p. 113).

Carina reflete o que está a sua volta e se vale do consumo para atingir seus objetivos. Lee Miller é a celebridade com quem ela quer se parecer, e a personagem move "mundos e fundos" para que isso aconteça, no que é bem-sucedida, ainda que, como visto, isso não lhe traga realização verdadeira. 


\section{O corpo liberado em "Bom partido"}

Perspectiva distinta apresenta a coletânea de contos Osso de baleia, de Lorena Otero, em que todos os textos orbitam em torno do corpo gordo, da gordofobia e da aceitação ou não dos padrões impostos pela sociedade. Destaco aqui o conto "Bom partido", narrado em primeira pessoa por uma mulher que sente na pele as imposições do namorado e a dificuldade dele em aceita-la publicamente, conforme sugerido nas primeiras linhas:

Ele era ótimo.

De todos os homens que já namorei ele foi um dos mais apaixonados. Quer dizer, não dá pra chamar de namoro, nem de apaixonado, porque ele tinha problemas com o significado de alguns termos. Tá certo que a gente se viu três vezes por semana durante seis meses, trocamos presentes, choramos juntos, compartilhamos sonhos, confessamos medos e até fizemos planos para o futuro, mas não dá pra falar que era um "namoro". Namoro é uma palavra muito forte. Mas ele era ótimo (OTERO, 2019, p. 23).

A adversativa "mas ele era ótimo" é reiterada ao longo do conto, dando contornos a uma linguagem irônica em que, pelo discurso da mulher em primeira pessoa, o leitor acessa o discurso do namorado, sempre rebaixando-a ou tentando convencê-la de que ela era complicada; de que ela falava demais; de que ela não reconhecia os esforços dele; de que não tinha bagagem cultural refinada para gostar das mesmas músicas ou para apreciar os mesmos pratos que ele. Além disso, demonstrava uma atenção difusa, citando muito de vez em quando algum projeto em que ela estivesse envolvida ou, ainda, o nome de algum amigo do sexo masculino. Isso também denota uma possessividade da personagem masculina por controlar a mulher, bem como a sua mania de interrompê-la, o que é chamado pelas feministas de "manterrupting" ou "macho palestrinha", isto é, aquele que apresenta dificuldade de ouvir e, principalmente, quer sempre impor suas verdades e seus discursos, numa clara tentativa de mostrar superioridade sobre a interlocutora.

Eu sempre fui insegura com a minha aparência e ele, em sua infinita maravilhosidade, só queria que eu conseguisse me ver pelos seus olhos. Por isso que eu queria emagrecer, sabe? Ele já me disse que eu ficaria mais bonita se fosse mais magra. Imagine isso? Ser tão bonita quanto ele achava que eu poderia ser! (OTERO, 2019, p. 25).

O corpo feminino tenta, então, adequar-se aos padrões e às expectativas de beleza sociais, que, como sabemos, dizem respeito a um corpo magro, já que magreza é sinônimo de beleza. No entanto, de modo surpreendente, o corpo refletido rebela-se, se reconhece como indivíduo cheio de potencialidades, con- 
forme expresso no final da narrativa: "Eu precisava de tudo que ele tinha para me oferecer. Sou muito grata pelo que vivi, mas precisei ir embora. É que eu aprendi tanto, melhorei tanto e cresci tanto, que fiquei grande demais pra ele." (OTERO, 2019, p. 25) Assim, a mulher que se apresenta aparentemente sujeita ao masculino consegue perceber o quão importante é a autovalorização e redefine seu lugar no mundo. Conforme Xavier:

A narrativa de autoria feminina, da década de 90 pra cá, vem apresentando protagonistas mulheres que passam a ser sujeitos da própria história, conduzindo suas vidas conforme valores redescobertos através de um processo de autoconhecimento. Este processo é exatamente o conteúdo da narrativa, que nos leva da personagem enredada nos "laços de família" ou nas próprias dúvidas existenciais à personagem, enfim, liberada (XAVIER, 2007, p. 169).

Também a personagem de Otero, enredada inicialmente numa proposta de relacionamento pouco saudável, em que seu parceiro colocava em xeque as fragilidades da moça, acaba optando por uma outra possibilidade - a da autoaceitação e do amadurecimento, o que lhe permite perceber que já não precisava mais permanecer naquela situação. Cabe aqui mais um comentário de Xavier sobre o percurso do corpo liberado: "A aceitação da 'inconstância', isto é, da fluidez, significa a liberação de esquemas predeterminados, coercitivos e repressores, própria de um corpo liberado." (XAVIER, 2007, p. 179) Em síntese, no conto "Bom partido" o corpo refletido é transgressor porque subverte as expectativas, tornando-se, então, um corpo liberado. Assim, este corpo liberado é o corpo livre das imposições e amarras sociais, ainda que, para isso, pague o preço da solidão, como assinala Xavier (2007, p. 181).

\section{O corpo envelhecido em $A$ ponta do silêncio}

Por fim, vamos nos deter numa obra que congrega, ao mesmo tempo, um corpo feminino envelhecido e violento: A ponta do silêncio, de Valesca de Assis. De acordo com Simone de Beauvoir, em $A$ velhice, "Já que o destino da mulher é ser, aos olhos do homem, um objeto erótico, ao tornar-se velha e feia, ela perde o lugar que lhe é destinado na sociedade" (BEAUVOIR, 1990, p. 152). Interessante destacar que vivemos numa sociedade hedonista ao extremo: a valorização do corpo magro e jovem é alardeada o tempo todo nos meios midiáticos. A mulher velha é aquela que não cumpre mais o papel estabelecido pelo sistema hegemônico, a saber, o de satisfazer os anseios sexuais masculinos e, mais ainda, perde sua função como procriadora. A literatura brasileira, como destaca Regina Dalcastagnè ao estudar personagens de romances publicados entre 1990 e 2004, apresenta um número relativamente pequeno de personagens maduras 
e, principalmente, quando aparecem, o padrão é o casal composto por um "galã maduro" e uma mulher bem mais jovem (DALCASTAGNÈ, 2005, p. 38), o que nos leva a refletir, ainda, sobre as diferenças no modo de se representarem o homem e a mulher velhos na literatura.

Sendo assim, a partir do que foi estabelecido por Elódia Xavier, propus, em outra oportunidade, uma tipologia do corpo envelhecido: i) o corpo envelhecido como degradação; ii) o corpo envelhecido silenciado; iii) o corpo envelhecido redimido (PEREIRA, 2019). ${ }^{4}$ Dentro da proposta deste artigo, a de estabelecer um entrecruzamento entre as categorias por ela estudadas, procedo agora à leitura de $A$ ponta do silêncio, narrativa em que se apresenta um corpo envelhecido que é, ao mesmo tempo, silenciado, violento e, porque violento, em certa medida, redimido.

Passemos ao enredo da obra: Marga, uma professora casada há 33 anos com Rudy Treibel e mãe de dois filhos, encontra-se num hospital, acometida que fora por uma espécie de crise nervosa e de um lapso sobre as circunstâncias que envolveram a morte de seu marido. Em capítulos curtos, narrado em primeira pessoa, o enredo mostra como essa mulher, de classe social pobre, casou-se com um homem rico que, a pouco e pouco, foi se mostrando uma pessoa cheia de preconceitos e violenta. A história se passa numa cidade do interior do Sul do país, com aproximadamente 50 mil habitantes, denominada Cruzeiro. No presente, como forma de organizar o pensamento, Marga recorre à rememoração e a uma escrita numa espécie de diário a que o leitor vai tendo acesso. ${ }^{5} \mathrm{Na}$ passagem a seguir, interpelada pelo delegado, um antigo aluno, ela reflete:

O delegado apareceu no fim da tarde. (...)

- Como aconteceu?

Tal como ontem, eu apenas abanava a cabeça, de um lado a outro, confusa e exausta. E chorava, incapaz.

Dentro do quarto, eu era uma velhinha a quem ele ajudava a atravessar a rua e chegar à casa. Mas a velhinha, perdida de si, não sabia mais onde morava. (...)

Desde o acontecido, minha vida tem sido mediada pelo que vejo e ouço, e pelo que escrevo (ASSIS, 2016, p. 19).

Lembranças entrecortadas vão dando conformidade à narrativa e ajudam a configurar um cenário de esfacelamento familiar, o que mostra que o romance problematiza a crise da família como instituição. Isso é corroborado pelo desfecho, em que os filhos, que não se entendem, participam de uma festa para um dos netos de Marga que acaba no trágico final de Rudy.

${ }^{4}$ No referido artigo analisei imagens do corpo feminino envelhecido em Clarice Lispector, Lygia Fagundes Telles e Maria Valéria Rezende.

${ }^{5}$ Esses cadernos usados por Marga lembram os cadernos da Barbie da protagonista Alice no romance Quarenta dias (2016, de Maria Valéria Rezende. 
Interessante mencionar que a personagem é professora e escreve para um jornal - sua carreira, por assim dizer, inicia-se com a bancarrota financeira do marido, inicialmente abastado -, ou seja, detém uma certa cultura e, ainda assim, é vítima de violência doméstica, o que aponta para o fato de que essa violência é sistêmica e ligada a hábitos culturais extremamente arraigados e misóginos, como se percebe na passagem a seguir:

(...) em nosso caso, meu e de Rudy, fingimos tão perfeitamente e por tanto tempo, que não cheguei a dar-me conta dos muros que Rudy foi construindo à nossa volta. Meu casamento, a partir de algum ponto, tornou-se um longo cerco, que acabou por deixar-me sem água e sem ar. Foi um metódico processo de aniquilamento (ASSIS, 2016, p. 26).

Fica claro que a protagonista sente-se presa, coagida, afinal, é até mesmo acusada por trabalhar fora de casa e supostamente não dar atenção suficiente à filha, Vívian, que se torna mãe solteira ainda bem jovem.

O capítulo "Cirlene, cena avulsa" é interessante por remeter à ideia de que o cerceamento até o limite das forças em um relacionamento é situação comum às mulheres: fica implícito, pelas colocações de Cirlene, esposa de Leonel, que ela passa situações, se não de todo iguais, ao menos parecidas com aquela vivida pela protagonista. Além disso, há uma certa linhagem de mulheres sofredoras na obra: tanto a mãe, como a filha e a neta estavam sujeitas à violência do patriarca: “Que solidão de mulheres amedrontadas!” (ASSIS, 2016, p. 41) Também seu passado familiar era o passado do medo: "O rosto da minha mãe era esquivo, impreciso. Continha o medo dela, e o da mãe dela, e o da mãe de minha avó, e assim até as portas do paraíso." (p. 56).

À medida que a protagonista descortina seu passado, ficam claras as ações violentas de Rudy, como quando ele arremessa a filha, ainda bebê, na cama, porque ela havia gofado em seu terno, o que acaba por causar-lhe uma luxação. De inicialmente sedutor a personagem masculina passa a controlador e depois a extremamente violento, num comportamento agressivo potencializado pelo uso da bebida. Tal controle é expresso pela substituição dos objetos da esposa pelos seus, o que indica a dessubjetivação da personalidade de Marga, que vê os elementos físicos que compõem sua vida serem substituídos por outros - como o colar que ganhara aos 15 anos, jogado na lata de lixo e substituído por uma joia mais cara. ${ }^{6}$

\footnotetext{
${ }^{6}$ Novamente aqui tem-se algo parecido no romance Quarenta dias, quando Alice deixa sua vida em João Pessoa e vai morar em um apartamento em Porto Alegre sem praticamente nada que fora seu, mobiliado pela filha, Norinha. Aqui, porém, o foco é a avosidade - uma suposta obrigatoriedade de que Alice cuidasse do futuro neto, agora que estava aposentada.
} 
Por fim, destaque-se um dos subterfúgios usados por Marga nos cadernos: algumas cartas escritas a Leonel, espécies de "carta-confissão", não exatamente do assassinato, como seria de se esperar, mas das circunstâncias familiares e pretéritas que levaram até aquele acontecimento:

Leonel, caro,

a pergunta é a mesma, sempre: por quê? por que fiz aquilo? Como pude matar, e com tal violência, eu, sempre tão mansa? É em busca da resposta, que devo a ti e aos meus filhos, que ando às voltas, dentro de mim. Olhando de longe, nenhum motivo parece suficiente: nem as indiferenças, nem as traições, nem a tortura psíquica. (...) (ASSIS, 2016, p. 33).

Olhando de perto, no entanto, pelas lembranças apresentadas, a personagem parece justificada aos olhos do leitor quando de sua reação final: ao tentar agredir a filha bêbado, Rudy escorrega, bate a cabeça e desmaia. Não reage às tentativas de ser acordado e, o que se segue, dá dimensão da fúria que possivelmente assolou Marga:

Morte pequena, morte muito pequena, mesmo para Rudy.

Depois disso? Nenhuma lembrança, nem a mais obscura imagem...

Sim, li que Rudy foi morto a facadas, raivosas facadas.

Sim, ouvi dizer que minhas mãos estavam sujas de sangue, meus óculos, o rosto, eu inteira suja de sangue, chegando ao hospital.

Sim, lei e ouvi dizer muitas coisas, mas, para mim, agora é o nada. Nada.

Nada (ASSIS, 2016, p. 83, grifo no original).

Inicialmente silenciada e submissa, a mulher, agora velha, finalmente reage. A violência reativa dá a tônica, como modo de resposta a todo um conjunto de opressões sofrido pela personagem ao longo da vida. De alguma forma, ela atinge o objetivo proposto a si mesma: "Preciso erguer a ponta deste silêncio, erguer a ponta deste grande e solitário tapete urdido dia a dia em todos esses anos, e que é a coberta de minha vida. Levantada a ponta, o resto virá por si, torrencial e caudaloso." (ASSIS, 2016, p. 58) De alguma forma, pela violência em si, pela rememoração, pela escrita e pelo bordado - como numa longa tradição ocidental de mulheres bordadeiras, Marga também borda -, a protagonista consegue tornar-se um corpo liberado, ainda que tenha de encarar as consequências de seus atos e, ao findar do romance, esteja no processo de autoconhecimento, não tendo este se efetuado por completo. 


\section{Considerações finais}

Conforme foi possível perceber pelas narrativas aqui estudadas, portanto, há uma tendência na literatura escrita por mulheres de trazer representações do corpo feminino as quais, por mais tenham passado por processos de violência, de degradação ou de espelhamento quanto às regras sociais, acabam por se libertar dos ditames sociais. Cabem aqui as reflexões de Xavier:

É satisfatório observar que o corpo liberado vem surgindo com certa constância em nossa literatura de autoria feminina, o que não acontecia antes. O que representa uma tendência social que permite às mulheres viverem plenamente "sua vocação de ser humano", sua sexualidade, enfim, sua transcendência, como queria Simone de Beauvoir (XAVIER, 2007, p. 196).

Agora, é possível transcender a violência ou regras disciplinares secularmente impostas às mulheres. Há novos caminhos e possibilidades que não o silenciamento para o corpo feminino. E a narrativa escrita por mulheres parece retratar de modo profícuo essas questões.

\section{Referências}

ANCHIETA, Isabelle. Imagens da mulher no Ocidente moderno 3: Stars de Hollywood. São Paulo: Editora da Universidade de São Paulo, 2019.

ASSIS, Valesca de. A ponta do silêncio. Porto Alegre: Besouro Box, 2016.

BEAUVOIR, Simone de. A velhice. 2. ed. Rio de Janeiro: Nova Fronteira, 2018.

DALCASTAGNÈ, Regina. A personagem do romance brasileiro contemporâneo: 19902004. Estudos de Literatura Brasileira Contemporânea, Brasília, n. 26, p. 13-71, jul.-dez. 2005.

LAURETIS, Teresa de. A tecnologia de gênero. In: HOLANDA, Heloisa Buarque de (Org.). Pensamento feminista: conceitos fundamentais. Rio de Janeiro: Bazar do Tempo, 2019.

OTERO, Lorena. Osso de baleia. Belo Horizonte: Quintal Edições, 2019.

PEREIRA, Maria do Rosário Alves. Corpo feminino e envelhecimento na obra de Lygia Fagundes Telles. Revista Estudos de Literatura Brasileira Contemporânea, Brasilia, n. 56, p. 1-9, 2019.

TELLES, Lygia Fagundes. Pomba enamorada ou uma história de amor. In: TELLES, Lygia Fagundes. Seminário dos ratos. Rio de Janeiro: Rocco, 1998. 
XAVIER, Elódia. Que corpo é esse? O corpo no imaginário feminino. Florianópolis: Editora Mulheres, 2007.

XAVIER, Elódia. Que corpo é esse? O corpo no imaginário feminino. 2. ed. Rio de Janeiro: Oficina Raquel, 2021.

WOLF, Naomi. O mito da beleza: como as imagens de beleza são usadas contra as mulheres. Rio de Janeiro: Rosa dos Tempos, 2018. 